http://www.nature.com/nri/index.html

\title{
Regulatory immune cells in transplantation
}

Kathryn J Wood, Andrew Bushell and Joanna Hester

Transplantation Research Immunology Group

Nuffield Department of Surgical Sciences

John Radcliffe Hospital

Oxford OX3 9DU

United Kingdom

\section{Key words}

Regulatory T cell, suppressor T cell, regulatory B cell, myeloid derived suppressor cell, regulatory macrophage, cell therapy, alloantigen, rejection, tolerance 


\section{Abstract}

Immune regulation is fundamental to any immune response to ensure that it is appropriate for the perceived threat to the host. Following cell and organ transplantation, it is essential to control the innate immune response triggered by the injured tissue and the adaptive immune response stimulated by mismatched donor and recipient histocompatibility antigens if the transplant is going to survive and function. Here, we discuss the leukocyte populations that can promote tolerogenic immune responses after cell or solid-organ transplantation. Such populations include regulatory T cells, B cells and macrophages, as well as myeloidderived suppressor cells, dendritic cells and mesenchymal stromal cells. We consider the potential of these regulatory immune cells to develop and function in transplant recipients and their potential use as cellular therapies to promote long term graft function. 


\section{Introduction}

The same leukocyte populations, including macrophages, dendritic cells, T cells and B cells, that participate in the events that result in the destruction of a cell or organ transplant can also play a role in promoting immune tolerance to the transplanted cells or tissue ${ }^{1}$. Regulatory immune cells that can prevent allograft rejection or graft versus host disease (GVHD) are specialised leukocyte populations that are either selected to have regulatory function, or whose differentiation is influenced by the microenvironment present either within the allograft or the draining lymphoid tissue enabling them to acquire immune regulatory properties. The presence of regulatory immune cells in a transplant recipient can shift the balance towards immune regulation and away from rejection or GVHD. Thus regulatory immune cells can play an important role in determining the long term outcome of a transplant.

Studies of transplantation provided some of the earliest evidence for the occurrence of immune regulation in vivo. Data from neonatal tolerance studies performed by Billingham, Brent and Medawar in the 1950s suggested that additional mechanisms beyond deletion of donor-reactive cells were involved in sustaining immune unresponsiveness to an allograft ${ }^{2}$. Later studies showed that rats with allografts that survived long term in the absence of continuous drug-based immunosuppression - a status referred to as operational transplantation tolerance - had T cells that could prevent graft rejection mediated by a subsequently transferred population of effector $\mathrm{T}_{\text {cells }}{ }^{3}$. This form of cellular regulation in transplantation was later shown to be associated with $\mathrm{CD}^{+}{ }^{+}$cells that express CD25, the $\alpha$-chain of the interleukin- 2 (IL-2) $)^{4-7}$, consistent with data examining immune regulation and the development of autoimmunity ${ }^{8}$.

In clinical transplantation, most recipients require life-long immunosuppressive drug therapy to prevent rejection and loss of the transplant. However, evidence that regulatory immune cells can contribute to the mechanisms that enable some transplants to function long term is accumulating. Studies of the small numbers of transplant recipients who have functioning kidney or liver allografts in the absence of immunosuppression have proved very informative. Individuals who exhibit operational tolerance to an organ allograft are rare but have been described in four clinical situations. First, recipients who have had their immunosuppressive drugs discontinued for medical reasons, including persistent viral infections and cancer, which are both side-effects of life-long treatment with non-specific immunosuppressive drugs. Second, recipients who are non-compliant, in other words who choose to stop taking the immunosuppressive drugs ${ }^{9}{ }^{10}$. Third, liver transplant recipients who have been participating in clinical studies, including immunosuppression weaning ${ }^{11}$. Fourth, kidney transplant recipients treated with tolerance induction protocols, such as those designed to induce mixed chimerism $^{12}$. Data characterising the immune status of these immunosuppressive drug-free transplant recipients has shown that regulatory $T\left(T_{\text {Reg }}\right)$ cells $^{13,14}$, regulatory $B$ cells ${ }^{15-17}$ and dendritic cells (DCs) may contribute to the state of operational tolerance in these transplant recipients.

In general, T cells have a central role in immune responses that lead to the destruction of transplanted cells, organs or tissues, as well as in controlling these unwanted immune responses. However, as demonstrated by 
the characterisation of the molecular signatures of tolerance in immunosuppression-free liver and kidney transplant recipients, other immune cell subsets can also have dual functionality, contributing to rejection or regulation depending on the origin of the cells and importantly the conditions that prevail in the transplant recipient. B cells, for example, can promote transplant rejection through their function as antigen-presenting cells (APCs) or by secreting alloantibody. More recently though, regulatory B cells have been shown to control immune responses after transplantation ${ }^{15,16}$.

In this Review, we summarize our current understanding of the regulatory immune populations that can promote tolerance during transplantation. Furthermore, we consider the clinical potential of targeting these populations in order to facilitate long-term survival and function of allografts in transplanted patients.

\section{Regulatory T cells}

Different populations of $\mathrm{T}$ cells with regulatory activity can contribute to the prevention of transplant rejection and GVHD, including $\mathrm{CD}^{+} \mathrm{T}_{\text {cells }}{ }^{7,18-21}, \mathrm{CD}^{+} \mathrm{T}_{\text {cells }}{ }^{22-24}, \mathrm{CD} 4 \mathrm{CD} 8^{-} \mathrm{T}_{\text {cells }}{ }^{25}$, NKT cells ${ }^{26,27}$ and $\gamma \delta \mathrm{T}$ cells ${ }^{28}$. Indeed, all of these subsets potentially have a role in promoting transplant tolerance at different stages of the response.

$C D 4^{+}$regulatory $T$ cells.

$\mathrm{T}_{\text {Reg }}$ cells that can control allograft rejection and GVHD in vivo can arise via two distinct pathways. Thymusderived or naturally occurring $\mathrm{T}_{\mathrm{Reg}}\left(\mathrm{nT}_{\mathrm{Reg}}\right)$ cells are selected in the thymus and function in the periphery primarily to suppress responses to self antigens ${ }^{19}$. $\mathrm{nT}_{\text {reg }}$ cells are present in every healthy individual and constitutively express high levels of the transcription factor forkhead box P3 (FOXP3). In the second pathway, $\mathrm{CD}^{+} \mathrm{T}$ cells that encounter antigen in a tolerogenic microenvironment in the periphery can differentiate into 'adaptive' or induced $\mathrm{T}_{\text {reg }}\left(\mathrm{iT}_{\text {reg }}\right.$ ) cells ${ }^{29}$. Similar to $\mathrm{nT}_{\text {reg }}$ cells, $\mathrm{iT}_{\text {reg }}$ cells sustain high levels of FOXP3 expression, and this is necessary for their suppressive functions. The cell surface and intracellular markers expressed by human and mouse $\mathrm{nT}_{\text {reg }}$ and $\mathrm{iT}_{\text {reg }}$ are shown in Table 1.

In solid-organ transplant recipients, there are usually insufficient numbers of $\mathrm{nT}_{\text {Reg }}$ cells at the time of transplantation to prevent rejection of a fully allogeneic graft (that is, when both MHC and minor histocompatibility antigens are mismatched). This is especially the case when donor-derived alloantigenreactive memory $T$ cells pre-exist in the transplant recipient ${ }^{30}$. In these situations, the frequency of donorderived alloantigen-reactive $\mathrm{T}$ cells present in the recipient's immune repertoire is far higher than the relatively small number of $\mathrm{nT}_{\text {reg }}$ cells that are present ${ }^{6}$, such that the balance is shifted away from regulation towards allograft destruction. However, the fact that $\mathrm{nT}_{\text {reg }}$ cells cannot prevent destruction of an allograft in the absence of immunosuppressive drugs, does not mean that these cells do not function, but instead suggests that they are overwhelmed by the high frequency effector immune cells. Interestingly, the allograft itself can induce $T_{\text {reg }}$ cells that can protect it from rejection ${ }^{31}$, and even when the primary allograft has been rejected, cells with characteristics of $T_{\text {reg }}$ cells are found in the recipients ${ }^{32,33}$. This confirms that exposure to alloantigen 
over a period of time can lead to the generation of $\mathrm{iT}_{\text {reg }}$ cells, even when the immune response has been destructive. Thus both $\mathrm{nT}_{\text {reg }}$ and $\mathrm{iT}_{\text {reg }}$ cells contribute to the overall pool of $\mathrm{T}_{\text {reg }}$ cells that can recognise and respond to donor alloantigens ${ }^{34}$. However, it is likely that after transplantation $\mathrm{iT}_{\mathrm{Reg}}$ cells that develop in response to donor-derived alloantigens may be more important that $\mathrm{nT}_{\mathrm{Reg}}$ cells for mediating long-term tolerance to the allograft due to the persistent presence of donor antigens ${ }^{35}$.

This critical balance between graft destruction and regulation can be shifted in several ways, either before or after transplantation, notably by employing strategies that increase the relative frequency or functional activity of alloantigen-reactive $\mathrm{T}_{\text {reg }}$ cells ${ }^{36-39}$, or by inhibiting the activity of effector $\mathrm{T}$ cells The use of immunosuppressive drugs that permit or promote $T_{\text {reg }}$ cell generation and function is obviously one approach that can be effective ${ }^{40}$, together with other strategies, including infusion of alloantigen before transplantation (to expand $n T_{\text {reg }}$ cells specific for donor alloantigens and promote $\mathrm{iT}_{\text {reg }}$ cell generation) ${ }^{41}$ or delivery of $\mathrm{T}_{\text {reg }}$ cells as a cellular therapy ${ }^{42}$ (this will be discussed later).

$\mathrm{nT}_{\text {reg }}$ and $\mathrm{iT}_{\text {reg }}$ cells use a number of different mechanisms to inhibit the activity of effector immune cells which, in the absence of $T_{\text {reg }}$ cells, trigger graft rejection or GVHD. For example, $T_{\text {reg }}$ cell expression of cytotoxic $T$ lymphocyte antigen 4 (CTLA4) can inhibit APC activity, thereby preventing the development of effector T cells. Furthermore, CTLA-4 binding to the co-stimulatory molecules CD80 and CD86 on APCs has been implicated in the activation of the enzyme indoleamine 2 3-dioxygenase (IDO) which ultimately results in both a local deprivation of the essential amino acid tryptophan and a local production of inhibitory molecules known as kynurenines, resulting in attenuated $\mathrm{T}$ cell proliferation ${ }^{43}$. $\mathrm{T}_{\text {reg }}$ cells can also produce IL-10 ${ }^{44}$, an immunosuppressive cytokine that can inhibit APC activity and promote the conversion of T cells into Tr1 cells and is likely important for regulatory activity in the draining lymphoid tissue as well as the allograft itself (see below). Indeed, blocking the activity of CTLA4 (CD152) or IL-10 in vivo prevents $\mathrm{T}_{\text {reg }}$ cell-mediated regulation in transplantation models ${ }^{6,41,45}$ (Figure 1). IL-10 can also be produced by other leukocyte populations, notably DC and regulatory B cells (see below). Thus Tr1 cells could be generated in vivo as a consequence of high levels of IL-10 being produced in defined microenvironments, including the draining lymphoid tissue and the allograft (Figures 1 and 2). Some studies have shown that TGF $\beta^{46,47}$ and IL-35 ${ }^{48}$ are also important for the functional activity of $\mathrm{T}_{\text {reg }}$ cells.

For $\mathrm{T}_{\text {reg }}$ cells to function efficiently they must be in the right place at the right time during the response to the allograft. The location in which $\mathrm{T}_{\text {reg }}$ cells function in vivo most likely changes with time after transplantation. There is evidence that $T_{\text {reg }}$ cells can reduce the impact of ischemia-reperfusion injury. To inhibit the activation of naïve $T$ cells and the development of an effector-type adaptive immune response, $T_{\text {reg }}$ cells function initially in the draining lymphoid tissue, thereby preventing the activation and proliferation of effector T cells. At later times following transplantation, $T_{\text {reg }}$ cells migrate to and function within the allograft itself ${ }^{49}$. Indeed, there is evidence that the allograft is an important site for providing continuous exposure of $T_{\text {reg }}$ cells to graft-derived antigen ${ }^{50}$, thereby creating an environment that is permissive to graft acceptance ${ }^{51,52}$. 
In addition to $\mathrm{nT}_{\text {reg }}$ and $\mathrm{iT}_{\text {reg }}$ cells, a number of other $\mathrm{CD}^{+}{ }^{\mathrm{FOXP3}} 3^{-}$regulatory $\mathrm{T}$ cell populations have been described. These include Tr1 cells, which are generated in the presence of high amounts of IL-10 ${ }^{53}$ and can function to inhibit GVHD, and TGF $\beta$-dependent IL-10-independent $T_{\text {reg }}$ cells, which have been detected in rodents that have accepted allografts. It is likely that, depending on the microenvironment created in vivo, the degree of histoincompatibility between donor and recipient, and the specific type of tissue that is transplanted, different $\mathrm{CD} 4^{+} \mathrm{T}_{\mathrm{Reg}}$ cell populations are involved in inhibiting destructive immune responses to the allograft.

CD8 ${ }^{+}$regulatory $T$ cells.

$\mathrm{CD}^{+} \mathrm{T}$ cells can suppress the activity of self-reactive $\mathrm{T}$ cells ${ }^{54}$ as well as effector $\mathrm{T}$ cell responses to alloantigens $^{55}$. The mechanisms used by $\mathrm{CD}^{+} \mathrm{T}$ cells to mediate suppression include both cytotoxic (such as the killing of effector T cells ${ }^{56}$ or APCs ${ }^{57}$ ) and non-cytotoxic pathways. In the 1980s, hypothetical suppressor cascades, involving the participation of multiple effector T cell subsets and a variety of secreted mediators, were proposed, but none of these was validated ${ }^{58,59}$ and interest in $\mathrm{CD} 8^{+}$T cell-mediated regulation waned.

The recent characterisation of $\mathrm{CD}^{+} \mathrm{CD} 28^{-}$and $\mathrm{IL}-10$-producing $\mathrm{CD} 8^{+}$regulatory $\mathrm{T}$ cells has revived interest in this field. $\mathrm{CD}^{+} \mathrm{CD} 28^{-} \mathrm{T}$ cells inhibit APC-mediated $\mathrm{T}$ cell activation by direct cell contact-dependent mechanisms ${ }^{60}$ and are most likely an end-stage population. Cells with this phenotype have been identified in renal transplant recipients that have received alemtuzumab induction therapy. Alemtuzumab, a monoclonal antibody that targets $\mathrm{CD}_{52}{ }^{+}$cells, results in profound leukocyte depletion when used as an induction therapy in transplant recipients. Leukocyte repopulation occurs gradually over time in response to the lymphopenic environment created following alemtuzumab therapy, with different leukocyte subsets repopulating at different rates ${ }^{61}$. $\quad \mathrm{CD}^{+} \mathrm{CD} 28^{-} \mathrm{T}$ cells that are present in renal transplant recipients treated with alemtuzumab induction therapy could play a role in suppressing the immune response to donor alloantigens in the longer term $^{62}$.

In contrast, IL-10-producing $\mathrm{CD} 8^{+} \mathrm{Tr}$ cells can be generated from naive $\mathrm{CD} 8^{+} \mathrm{T}$ cells and inhibit primary $\mathrm{T}$ cell responses through IL-10. IL-10-producing regulatory $\mathrm{CD}^{+} \mathrm{Tr}$ cells share many similarities with the $\mathrm{CD} 4^{+} \operatorname{Tr} 1$ cells mentioned above, in that both populations are anergic (that is, refractory to restimulation with cognate antigen), their generation depends on IL-10 and both suppress primary T cell responses through IL-10-, but not TGF- $\beta$ dependent mechanisms. IL-10-producing $\mathrm{CD}^{+} \mathrm{Tr}$ cells have been described in vivo in a patient with long-term acceptance of an allogeneic kidney transplant ${ }^{63}$. These findings suggest that there may be two distinct subsets of $\mathrm{CD}^{+}$regulatory $\mathrm{T}$ cells, namely $\mathrm{CD} 8^{+} \mathrm{CD} 28^{-}$regulatory $\mathrm{T}$ cells and $\mathrm{CD} 8^{+} \mathrm{IL}-10$ producing $\mathrm{Tr}$ cells, that use distinct tolerogenic mechanisms and are generated in vivo in response to different microenvironments; $\mathrm{CD} 8^{+} \mathrm{CD} 28^{-}$regulatory $\mathrm{T}$ cells in response to lymphopenia, $\mathrm{CD} 8^{+} \mathrm{Tr}$ cells in response to IL10. A kinetic analysis to determine the presence of each of these subsets in transplant recipients treated with different immunosuppressive drug regiments is required to understand their relative roles in controlling immune responses to donor alloantigens after organ transplantation 
CD4 $C D 8^{-}$regulatory $T$ cells.

Peripheral $\alpha \beta-\mathrm{TCR}^{+} \mathrm{CD} 3^{+} \mathrm{CD} 4^{-} \mathrm{CD} 8^{-} \mathrm{NK} 1.1^{-} \mathrm{T}$ cells so called double negative (DN) $\mathrm{T}$ cells have been shown to inhibit immune responses mediated by $\mathrm{CD}^{+}$and $\mathrm{CD}^{+} \mathrm{T}$ cells and to prevent allograft rejection ${ }^{64,65}$, graft versus host disease ${ }^{66}$ and diabetes ${ }^{67}$. DN T cells use a variety of mechanisms to mediate suppression, including antigen-specific killing of $\mathrm{CD}^{+}$or $\mathrm{CD}^{+} \mathrm{T}$ cells via the Fas-FasL pathway, promoting the downregulation of the costimulatory molecules CD80 and CD86 on DCs, inducing DC apoptosis, and acquiring alloantigens from DCs by trogocytosis. Recently, IFN $\gamma$ expression was found to be induced in DN T cells by autologous tolerogenic DCs (see below) and this led to the accumulation of DN T cells in the spleens of rats that were operationally tolerant to a heart allograft. Notably, blockade of IFN $\gamma$ resulted in allograft rejection ${ }^{68}$.

Human DN T cells share phenotypic and functional features with their mouse counterparts, including the ability to acquire peptide-HLA complexes from APCs by a cell-contact-dependent manner and the ability to induce apoptosis of antigen-specific $\mathrm{CD}^{+}{ } \mathrm{T}_{\text {cells }}{ }^{69}$. In patients that have received an allogeneic hematopetic stem cell transplantation (HSCT), deficiency of DN T cells was associated with the occurrence of GVHD. This provides evidence, albeit limited, that $\mathrm{CD}^{-} \mathrm{CD} 8^{-} \mathrm{DN} \mathrm{T}$ cells with regulatory activity can participate in the development of peripheral tolerance in humans ${ }^{70}$.

NKT cells.

Natural killer T (NKT) cells have been implicated in transplant rejection and tolerance ${ }^{71}$ as a result of their unique capacity for rapid and early production of pro-inflammatory or anti-inflammatory cytokines in response to their cognate glycolipids antigens presented on CD1 molecules. Mouse bone marrow $\mathrm{CD}^{-} \mathrm{CD} 8^{-} \mathrm{T}$ cells, the majority of which are NKT cells, were found to inhibit acute lethal GVHD by augmenting proliferation of donor-derived $\mathrm{T}_{\text {reg }}$ cells in an IL-4-dependent manner ${ }^{72,73}$. Furthermore, in a mouse model of HSCT, the adoptive transfer of highly purified (>95\%) NKT cells suppressed GVHD, decreased the production of IFN $\gamma$ and TNF by donor-derived T cells but left the graft-versus-tumour response intact ${ }^{74}$.

$\gamma \delta T$ cells.

$\gamma \delta \mathrm{T}$ cells are nonconventional $\mathrm{T}$ cells that have important roles in anti-tumour and anti-viral immune responses. An altered distribution of $\mathrm{V} \delta 1$ and $\mathrm{V} \delta 2$ subsets have been observed in operationally tolerant liver transplant recipients ${ }^{75,76}$, but experimental data on whether $\gamma \delta$ T cells can protect the allograft is limited. A tissue-homing population of $\gamma \delta \mathrm{T}$ cells has been shown to exert local regulatory activity in non-transplant settings ${ }^{77}$, but a specific functional role of $\gamma \delta$ T cells in mediating transplant tolerance has yet to be described.

\section{Regulatory B cells}

Interest in the role of regulatory B cells in transplantation was stimulated by clinical rather than experimental data. A B cell signature, that is an expansion of B cells in the absence of donor specific alloantibody and expression of mRNA for genes known to be associated with B cell function, including CD20 and CD79b, 


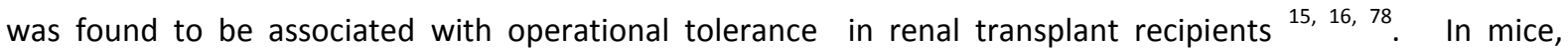
regulatory B cells express high levels of CD1d, CD21, CD24 and IgM and moderate levels of CD19, although some heterogeneity may exist ${ }^{79}$. Human regulatory $B$ cells, $C D 19^{+} \operatorname{CD} 24^{\text {hi }} \operatorname{CD} 38^{\text {hi }}$, comprise a small subset of the total B cell pool and share some properties with their mouse counterparts including an immature phenotype (Table 1). One of the characteristics of B cells with regulatory activity is their ability to secrete IL-10, a cytokine known to favour immune regulation as discussed above (Figure 1). The ability of IL-10-secreting B cells to regulate an immune response was first demonstrated in autoimmunity ${ }^{80-82}$. CD40 stimulation appears to be required to stimulate IL-10 production by regulatory B cells and has been reported to be necessary for activation of Breg enabling them to manifest their functional activity and suppress Th1 cell differentiation ${ }^{83}$. CD40-activated human Breg induce the generation of Treg cells from allogeneic $\mathrm{CD}^{+} \mathrm{T}$ cells ${ }^{84}$, but whether or not this is dependent on B cell derived IL-10 remains to be clarified. In comparative studies using cells from the same donor, Breg cell-induced Treg cells showed more potent suppressive activity than pDC-induced Treg cells ${ }^{85}$.

How Breg are generated in response to alloantigen, as well as when and where they function in vivo, remains to be clarified in transplant recipients. Experimental studies examining the role of Breg in vivo in transplantation are limited at present. In mice, TIM-1 ligation on B cells induced TIM-1 ${ }^{+}$B cells with regulatory activity ${ }^{86}$, suggesting a potential therapeutic strategy for increasing the number of Breg in vivo. Other studies have shown that $\operatorname{lgM}^{+}$, but not $\operatorname{lgG}^{+} B$ cells form clusters within kidney allografts in tolerant rats a finding that has been interpreted as indicating the presence of B cells with regulatory activity ${ }^{87}$. Our own work investigating the evolution of Breg during leukocyte reconstitution in kidney transplant recipients treated with alemtuzumab demonstrates that Breg appear transiently in the peripheral blood following transplantation ${ }^{88}$ and their presence is potentially related to the later presence of Treg cells in recipients receiving induction therapy ${ }^{89,90}$. The link between Breg and Treg cell function in protection against allograft rejection requires further study.

Some populations of B cells have the capacity to induce specific immunological unresponsiveness to alloantigens in vivo; an additional pathway where B cells can contribute to the induction of operational tolerance to alloantigens. Transitional B cells are poor APCs in vitro, where they show low co-stimulatory function ${ }^{91}$. In keeping with this, small resting $B$ cells have been shown to induce tolerance to alloantigens. This ability of resting $B$ cells to present donor-derived alloantigens to the host immune system in a nonstimulatory form may be important therefore for promoting tolerance to allografts in some situations when donor leukocytes are infused into transplant recipients ${ }^{92}$.

\section{Regulatory macrophages}

Macrophages have both protective and pathogenic functions and can be divided into subgroups on the basis of their tissue location and their functional properties ${ }^{93}$. In transplantation, macrophage activation occurs initially as a result of the tissue injury that is associated with ischemia and reperfusion, and these cells can 
contribute to early graft damage ${ }^{94}$. However, alternatively activated macrophages can inhibit the production of pro-inflammatory cytokines by classically activated macrophages and also have important roles in wound healing and tissue repair. This function is important in organ transplantation in the early post-transplant period, as wound healing allows tissue homeostasis to be re-established. However, later after transplantation, tissue repair responses may be less desirable as they have been shown to contribute to delayed allograft failure by causing occlusion of blood vessels within the allograft, a process referred to as 'transplant arteriosclerosis' or 'transplant-associated vasculopathy'.

It has been proposed that 'regulatory macrophages' may represent an additional, distinct macrophage population whose main physiological role is to dampen pro-inflammatory immune responses ${ }^{95}$. However, to date, no stable, convenient surface markers for regulatory macrophages have been identified. Regulatory macrophages produce high amounts of IL-10 (a common feature of leukocytes with immunoregulatory properties), but unlike alternatively activated macrophages, do not express arginase and are not dependent on STAT6 signalling. Interaction with $\mathrm{T}_{\text {reg }}$ cells can lead to macrophages acquiring the properties of alternatively activated or regulatory macrophages ${ }^{96}$ (Figure 2). Furthermore, the interaction of macrophages with B-1 B cells results in the formation of a regulatory macrophage population ${ }^{97}$.

Human regulatory macrophages isolated from the peripheral blood are characterised by their morphology, cell surface phenotype (Table 1) and their ability to suppress T cell proliferation in vitro. In a pilot clinical study, human regulatory macrophages were shown to reduce the need for immunosuppressive drugs when administered to kidney transplant recipients ${ }^{98}$. Host macrophages can also have a protective effect following transplantation. Reducing the pool of the host macrophages in recipient mice increased donor $\mathrm{T}$ cell expansion and aggravated GVHD after allogeneic $\mathrm{HSCT}^{99}$.

\section{Tolerogenic dendritic cells}

DC are crucial for priming antigen-specific T cell responses, including T cells responses to alloantigens ${ }^{100}$. However, they can also promote tolerogenic responses ${ }^{1,101-103}$ (Table 1).

Initially, immature conventional myeloid DCs that express low levels of MHC class II and costimulatory molecules at the cell surface were identified as the dominant form of $D C$ that had the capacity to induce $T$ cell tolerance ${ }^{104}$. Indeed, immature DCs can promote tolerance to solid-organ allografts and bone marrow grafts 101. For example, a single injection of immature donor-derived DCs 7 days before transplantation of a MHCmismatched heart allograft extends ${ }^{105}$ or prolongs survival of the allograft indefinitely ${ }^{106}$. Injection of donorderived DCs prevents the rejection of MHC-mismatched skin grafts ${ }^{107}$ and protects recipient mice from developing lethal acute GVHD ${ }^{108}$. The tolerogenic effects of immature DCs can be enhanced by coadministering these cells with other immunomodulatory agents, such as drugs that block the CD40-CD40L costimulatory axis ${ }^{109}$. 
Plasmacytoid DC (pDCs) pcan also promote tolerance in transplantation ${ }^{110}$. In experimental models, pDCs acquired alloantigen in the allograft and then migrated to the draining lymphoid tissue, where they induced the generation of Treg cells ${ }^{111}$. In mice, pre-pDC appear to be the principal cell type that facilitates hematopoietic stem cell engraftment and induction of donor-specific skin graft tolerance in allogeneic recipients ${ }^{112}$.

Higher numbers of pDCs than of myeloid DCs were found in the peripheral blood of paediatric liver transplant recipients that were operationally tolerant to their allograft. In the same study, a similar trend was seen in patients receiving low-dose immunosuppressive therapy during prospective immunosuppressive drug weaning, compared with patients on maintenance immunosuppression ${ }^{113}$. In addition, higher levels of expression of PD-L1 and CD86 by pDCs was found to correlate with elevated numbers of CD4 $4^{+} \mathrm{CD} 25^{\text {hi }} \mathrm{FOXP3}{ }^{+}$ Treg cells in liver transplant recipients who were free from immunosuppressive drug regimens ${ }^{114}$. These data suggest that pDCs may contribute to immune regulation in liver transplant recipients (Figure 1).

In summary, both myeloid DCs and pDCs can promote tolerance to alloantigens, and DC maturation in itself does not appear to be the distinguishing feature that separates immunogenic DC functions from tolerogenic ones ${ }^{115}$. However, despite the tolerogenic functions of DCs discussed above, the use of DCs to facilitate the induction of operational tolerance is not without risk. DCs are arguably better known for their ability to prime the immune system. Indeed, DCs pulsed with antigen are being used clinically as vaccines to stimulate immune responses to tumour antigens. Using DCs as a cellular therapy in transplantation may therefore carry the risk of sensitising the recipient. One possible approach to reducing this risk is to combine DC administration with co-stimulatory blockade, with the objective of presenting donor alloantigens to induce $T$ cell unresponsiveness.

\section{Myeloid-derived suppressor cells}

Myeloid-derived suppressor cells (MDSCs) are a heterogeneous population of progenitor cells that have been associated with many suppressive immune functions. MDSCs can accumulate in tissues during inflammation, where they may further differentiate into macrophages, DCs and granulocytes. The expansion and activation of MDSCs are regulated by factors produced by other cells that are present in the same microenvironment, including stromal cells, activated T cells and in tumours, the tumour cells themselves.

Several MDSC subsets have been described in both mice and humans ${ }^{116}$. Despite their heterogeneity, common phenotypical markers are expressed by most MDSCs, including Gr1 and CD11b in mice, and CD33, CD11b, CD34 and low levels of MHC class II I human (Table 1). Activated MDSCs suppress proliferation and cytokine production by effector T cells, B cells and NK cells in vitro through mechanisms that include their expression of inducible nitric oxide synthase 1 and arginase 1. MDSCs also appear to be able to inhibit T cell proliferation and modify $\mathrm{T}$ cell differentiation pathways. For example, they can promote Treg cell differentiation in a process requiring IFN $\gamma$ and IL-10 117 (Figure 2). Interestingly, interactions between MDSCs and macrophages results in a shift of macrophages towards an alternatively activated phenotype ${ }^{118}$. 
In experimental transplant models, MDSCs have been shown to promote tolerance to alloantigens. Direct evidence of a tolerogenic role for MDSCs has been obtained for heart and islet allografts in mice ${ }^{119,120}$ and by iNOS-expressing MDSCs in a rat kidney allograft model ${ }^{121}$. In bone marrow transplantation, indirect evidence for a role of MDSCs has come from the observation that transplantation tolerance could not be induced in mice that did not express MHC class II on circulating leukocytes, although given that many other leukocytes populations may also be altered in this setting ${ }^{122}$. The mechanisms used by MDSCs to promote tolerance to alloantigens require further clarification. Some evidence suggests that they may act partly through the induction or sparing of $\operatorname{Treg}^{121}$. Alternatively, MDSCs have been found to upregulate heme oxygenase 1, an enzyme that has immunoregulatory activity through the inhibition of DC maturation and preservation of IL-10 function as well as cytoprotective properties ${ }^{123}$.

\section{Mesenchymal stromal cells}

Mesenchymal stromal cells (MSCs) are a sub-population of multipotent cells within the bone marrow that support haematopoiesis and possess immunomodulatory and reparative properties ${ }^{124}$. Bone marrow derived MSCs have the ability to migrate to sites of inflammation, including to an allograft ${ }^{125}$. When MSCs are exposed to an inflammatory microenvironment they have been found capable of regulating many immune effector functions. Notably, MSCs have been shown to promote the generation of $\mathrm{T}_{\text {reg }}$ cells both in vitro and in vivo through mechanisms involving PGE $2, \mathrm{TGF}-\beta$ and cell-cell contact ${ }^{126,127}$. .

The impact of MSCs on the generation of $\mathrm{T}_{\text {reg }}$ cells may be indirect, as DCs repeatedly exposed to MSCs are maintained in an immature-like state ${ }^{128}$ (Table 1). In transplantation, retrieval and transplantation of the allograft inevitably results in ischemia and reperfusion injury creating an inflammatory microenvironment within the graft. The recruitment of MSCs to the graft in the early post-transplant period could potentially lead to the conversion of T cells also recruited into the allograft into $\mathrm{T}_{\text {reg }}$ cells. In addition, MSCs have been suggested to promote acceptance of allogeneic islets of Langerhans by secreting matrix metalloporoteinases ${ }^{125}$. The immunomodulatory properties of MSCs on B cell function could also contribute to suppressing graft rejection by inhibiting alloantibody production ${ }^{129}$.

\section{Interaction of distinct regulatory cell populations in transplantation}

Organ and tissue retrieval inevitably results in tissue damage and this, together with ischemia-reperfusion injury associated with the surgical procedures required to transplant a solid organ graft, triggers activation of the innate immune system resulting in inflammation in the allograft with hours after transplantation ${ }^{1}$. As already highlighted, MDSC and MSCs migrate to the site of an inflammatory response and are activated by the inflammatory cytokines present ${ }^{124}$. Thus early in the response to a transplant, these two populations may infiltrate the allograft and develop immunomodulatory activity (Figure 2). Donor-derived DCs and macrophages present in the allograft, as well as leukocytes attracted to the site of inflammation, might be influenced by the activity of either MDSCs or MSCs promoting some cells to develop regulatory properties. The inflammatory environment within the allograft also triggers the migration and maturation of resident 
donor derived DC to the draining lymphoid tissue where they initiate $\mathrm{T}$ cell activation ${ }^{130}$; the absence of secondary lymphoid tissue is sufficient to prevent rejection of vascularised organ allografts in naïve recipients $^{131}$. Activated $\mathrm{T}$ cells returning to the allograft may therefore encounter a tolerogenic microenvironment created by the presence of MDSC and MSC and if this occurs, iTreg cells may be generated.

nTreg cells and Breg will naturally be present in transplant recipients, and although the frequency of cells that can respond to donor alloantigens will be relatively low before transplantation, both cell populations will have the potential to migrate to the allograft where they can contribute to modulating the immune response (Figure 1). In addition, depending on the microenvironment present in vivo, donor alloantigen presented by donor-derived or recipient APCs could drive the generation or expansion of regulatory T or B cell populations. However, it is important to remember that despite active regulation occurring in the allograft and periphery, in the absence of any other forms of immunosuppressive therapy, the balance between rejection and regulation is tipped in favour of rejection or GVHD in recipients transplanted with a graft that is mismatched for major and/or minor histocompatibility antigens. Thus the immune regulatory cells pre-existing in the recipient or generated during the course of the response are not sufficiently powerful or present early enough in the evolution of the response to control the high frequency of leukocytes capable of destroying the graft.

\section{Impact of immunosuppressive drugs on regulatory populations}

Most transplant recipients are treated with a combination of immunosuppressive drugs and biological agents to control the rejection and GVHD responses. The combination of drugs used varies depending on the organ, tissue or cells transplanted as well as the protocols used by individual transplant programmes. In some transplant centres, kidney recipients may be given induction therapy using a monoclonal antibody or polyclonal antibody preparation, such as alemutuzumab or anti-thymocyte globulin, at the time of transplantation. This treatment significantly depletes the majority of leukocytes in the peripheral blood and can affect the lymphoid organs creating lymphopenia. Not all leukocyte populations will be affected to the same extent. For example memory $T$ cells are not depleted following alemtuzumab administration ${ }^{61,} 132$. Leukocyte repopulation is triggered by the lymphopenic environment and different leukocyte subsets repopulate at different rates. Interestingly, leukocyte depletion has the potential to tip the balance in favour of immune regulation by creating a situation where regulatory immune cells outnumber effector cells. In alemtuzumab treated transplant recipients there is evidence that $T_{\text {reg }}$ and $B_{\text {reg }}$ cells are present amongst the repopulating leukocytes and they may contribute to preventing rejection ${ }^{88-90}$. Anti-thymoycte globulin has also been shown to promote the generation of $\mathrm{T}_{\text {reg }}$ cells ${ }^{133}$..

Irrespective of whether leukocyte depletion therapy is used, transplant recipients will be treated with other immunosuppressive drugs, most likely a calcineurin inhibitor, such as tacrolimus or cyclosporine $A$, and an antiproliferative agent, such as mycophenolate mofetil. Calcineurin inhibitors and anti-proliferative agents can impact the generation and function of some regulatory immune cell populations. However, they also inhibit effector $\mathrm{T}$ cell activation, hence rationale for their use in clinical transplantation. Interestingly, $\mathrm{T}_{\text {reg }}$ cells can 
still be found in the peripheral blood of kidney transplant recipients treated with calcineurin inhibitors ${ }^{134,135}$ and in liver transplant recipients treated with tacrolimus and steroids after immunosuppression has been weaned and withdrawn ${ }^{13}$. Many transplant recipients are now also treated with a monoclonal antibody targeting CD25, the $\alpha$ chain of the IL-2 receptor (IL-2R). $T_{\text {reg }}$ cells express high levels of CD25 and indeed need IL-2 for generation and expansion. Thus the impact of anti-IL-2R therapy on the generation and function of regulatory cells, particularly $T_{\text {reg }}$ cells, is also debatedSome transplant recipients are treated with sirolimus, an immunosuppressive drug that targets the molecular target of rapamycin (mTOR) pathway. Interestingly sirolimus has been shown to support the generation of $\mathrm{T}_{\text {reg }}$ cells ex vivo ${ }^{136}$ and promote the function of infused Treg cells in vivo ${ }^{40}$. Thus the precise cocktail of immunosuppressive agents used in a transplant recipient may have differential effects on both effector and regulatory immune cells.

The use of combinations of immunosuppressive agents in clinical transplantation highlights the challenges associated with designing protocols that include the infusion of immune regulatory cell populations. The balance between rejection and graft survival can clearly also be modified by the infusion of defined populations of regulatory immune cells. As shown by adoptive transfer studies, the infusion of regulatory immune cells shortly before or at the time of transplantation, or even during a graft rejection episode, clearly has the potential to inhibit the activity of effector cells and promote graft acceptance ${ }^{35,42}$. The infusion of distinct populations of regulatory cells also enhances the generation and function of host regulatory immune cells (Figures 1 and 2). Co-administration of immunosuppressive drugs has the potential to enhance the functional properties and generation of regulatory immune cells, but some combinations of drugs may inhibit the activity of regulatory cells. Thus the competing actions of each component of an immunosuppressive protocol need to be considered very carefully as new protocols are defined for clinical trials. More work is needed to define the complex effects that different immunosuppressive agents have on immune regulatory cells. . This information is essential for the effective clinical translation of cell therapies in transplantation, as discussed below.

\section{Clinical translation of regulatory cell therapies in cell and organ transplantation}

Cellular therapies using Treg cells, regulatory macrophages, and mesenchymal stromal cells to suppress rejection or GVHD are being developed for application to clinical transplantation (Figure 3).

\section{Treg cell therapy}

In animal models, the transfer of Treg cells, with or without manipulation ex vivo, has proved to be a very effective strategy for controlling acute ${ }^{6,137}$ and chronic allograft rejection ${ }^{138,139}$ and also for preventing $\mathrm{GvHD}^{140}$. These studies provide proof-of-concept data to support the clinical translation of this approach. However, defining the most effective source and population of Treg cells for therapeutic use in humans does present some challenges. 
In the setting of bone marrow transplantation, a small number of clinical studies have infused Treg cells infusion in an attempt to limit GVHD (Table 2). Expanded nTreg cells were used to treat 2 patients who developed GVHD following bone marrow transplantation and clinical improvement was demonstrated in both patients ${ }^{141}$. In a dose escalation study, $\mathrm{CD} 25^{+} \mathrm{CD} 4^{+} \mathrm{FOXP} 3^{+}$cells were isolated from cord blood and expanded ex vivo for 24 hours in the presence of beads coated with CD3- and CD28-specific antibodies, before being infused into adult patients receiving HSCT. This study did not give rise to any safety concerns and when the data were compared to that from historical controls, a slight reduction in GVHD grades II-IV was observed ${ }^{142}$. Expanded donor-derived $\mathrm{CD} 25^{+} \mathrm{CD} 4^{+}$nTreg have also been infused into HLA haploidentical HSCT recipients, again in a dose escalation study. Encouragingly, this was found to prevent GVHD in the absence of any immunosuppressive treatment regimen, and to promote lymphoid reconstitution, improve immunity to opportunistic pathogens, and not weaken the graft-versus-leukaemia effect ${ }^{143}$. In organ transplantation, The One Study, a multi-centre Phase I/II study funded by the European Union FP7 programme will investigate the safety of infusion of ex vivo expanded nTreg and Tr1 cells into kidney transplant recipients (www.onestudy.org ).

An alternative approach, involving the use of IL-2 and rapamycin to enhance Treg cell function in situ in mice, was shown to be effective for the treatment of acute GVHD ${ }^{144}$. Low dose IL-2 therapy has also been used successfully to treat patients with chronic graft versus host disease ${ }^{145}$, and resulted in an increase in the number of Treg cells to a median of more than 5 times the baseline levels. Importantly, the low dose IL-2 therapy expanded Treg cell populations without affecting the function of conventional CD4 ${ }^{+}$T cells. Whether the same would hold true in a solid organ transplant recipient remains to be determined.

One of the concerns about the use of Treg cells clinically is whether this will lead to global immunosuppression. If so, it could be argued that Treg cell-based therapies offer no advantage over current immunosuppressive regimens. This issue has been addressed in mice. Following bone marrow transplantation, animals that were injected with Treg cells during solid organ transplantation were subsequently able to control $\mathrm{CMV}^{146}$ and influenza virus infections ${ }^{147}$. Importantly, in humans there is no evidence for an increase in susceptibility to infections in patients infused with Treg cells ${ }^{143}$. Moreover, Treg cell infusion has been shown to prevent GVHD while maintaining the graft versus leukaemia effect that occurs during bone marrow transplantation ${ }^{20}$. Clearly, this parameter that will require careful monitoring in future clinical studies.

A second concern is the heterogeneity of the FOXP3 ${ }^{+}$Treg cell populations characterised to date. Currently, there are no markers that can accurately discriminate human Treg cells from other T cells. For example, although Treg cells have been associated with a $\operatorname{CD} 25^{\text {hi }} \mathrm{CD} 127^{\text {low }}$ phenotype, activated T cells also upregulate CD25 and downregulate CD127. Thus populations isolated on the basis of expression of one or both of these markers may contain contaminating effector T cells. The addition of immunosuppressive agents, such as rapamycin, to the expansion cultures has been shown to increase the purity of $T_{\text {reg }}$ cells by eliminating non- $T_{\text {reg }}$ 
cells present in the starting population ${ }^{136}$. As such, the immunosuppressive drugs used in transplantation may reduce the the impact of contaminating cells. However, careful consideration will need to be given to the immunosuppressive drug protocol, as calcineurin inhibitors have been suggested in some studies to attenuate $T_{\text {reg }}$ cell function.

\section{Regulatory macrophage cell therapy}

Regulatory macrophages isolated from the organ donor have been administered intravenously to two recipients of living donor kidney transplants with no deleterious impact on graft function and enabling tacrolimus immunosuppressive therapy to be reduced within the first 24 weeks after transplantation ${ }^{98}$. Following administration, regulatory macrophages remained viable and trafficked from the lungs via the blood to liver, spleen, and bone marrow. Studies to define the mechanism responsible for graft survival following infusion of regulatory macrophages revealed that at 1 year after transplantation the patterns of gene expression found in the peripheral blood of the patients treated were similar to those described for tolerant kidney transplant recipients by the Indices of Tolerance/RISET European Networks ${ }^{15}$ (Table 3). A follow up study using regulatory macrophages in kidney transplant recipients will be performed as part of The ONE Study.

\section{Mesenchymal stromal cell therapy}

Bone marrow derived MSCs to be used in cell or organ transplantation could be autologous, donor-derived (allogeneic) or third party (allogeneic, derived from neither recipient nor donor). Autologous cells are clearly the safest option for clinical cell therapy in terms of the relative risk of rejection or graft versus host reactions. However, there are circumstances in which healthy autologous, HLA matched or haploidentical cells will not be available, and in such situations third party allogeneic MSCs could provide an immediate source of cells ready for clinical cell therapy. Intravenous administration has been shown to be suitable route for MSC infusion, butan additional possibility would be to infuse MSCs into the donor organ prior to transplantation or to cotransplant them at the site of the allograft ${ }^{125}$.

The number of bone marrow derived MSCs infused in the clinical studies reported to date has ranged from $0.4 \times 10^{6}$ to $10 \times 10^{6} /$ per $\mathrm{kg}$ of bodyweight ${ }^{148,149}$ with no significant correlation between the dose of MSCs received and clinical outcome. Single, double and repeated infusions have been administered, with no obvious pattern to the outcome observed in each variation of the protocol. For example, some patients responded to a second infusion following a non-response to the first, while others failed to respond even after multiple infusions ${ }^{148}$. Not all clinical studies using MSCs to modulate immune reactivity have reported positive data. A significant placebo effect was observed in phase III clinical trials that used third-party MSCs to treat GVHD ${ }^{150}$. In contrast, treatment with MSCs was found to correlate with a significant improvement in patients with steroid-resistant liver or gastrointestinal GVHD ${ }^{150}$. In kidney transplantation, infusion of patients with autologous MSCs resulted in a lower incidence of acute rejection, a decreased risk of opportunistic infection, and better estimated renal function at 1 year post-transplantation ${ }^{151}$. 
Although over 100 clinical trials investigating the immunomodulatory and pro-reparative effects of MSC are in progress (www.clinicaltrials.gov) this form of cell therapy is still at an early stage of development. The results of these trials will undoubtedly provide further insight into the application of therapeutically administered MSC in transplantation.

\section{Other forms of cell therapy}

Other forms of cell therapy also have potential for use in clinical transplantation as highlighted by the experimental data reviewed above. Clinical trials using immunotherapeutic DC to stimulate immune responses in patients with cancer and to restore self tolerance in patients with type 1 diabetes are in progress ${ }^{152}$. Implementation of human DC therapy in clinical transplantation still requires a number of key issues to be optimised and finalised including the methodology for DC isolation and purification ${ }^{153}$, the source of DC, route and timing of administration, as well as the most appropriate form of adjunctive immunosuppressive therapy.

\section{Conclusion}

Immune regulation is a complex process that involves multiple mechanisms and, more often that not, the cooperation of distinct cell populations. Transplantation is no exception to this rule, and multiple regulatory cells can play roles at different stages of allograft response. Interestingly, one of the common features of many of regulatory leukocytes is their ability to produce IL-10, a cytokine that can create a microenvironment that facilitates regulation and may function to enhance the generation and function of regulatory immune cells throughout the post-transplant course. Transplant recipients are treated routinely with immunosuppressive drug therapies, some of which may inhibit the generation or function of regulatory immune cells. Currently, lifelong treatment with these drugs is normally used to prevent the risk of graft rejection. Understanding the impact of immunosuppressive drugs on the function and generation of regulatory immune cells is an important step for the successful clinical translation of novel cell therapies. The goal of introducing regulatory immune cell therapy in clinical transplantation is to improve long term outcomes after transplantation.

\section{Acknowledgements:}

The work from the authors' own laboratory described in this review was supported by grants from The Wellcome Trust, Medical Research Council UK, British Heart Foundation, Roche Organ Transplant Research Foundation and the European Union through the Indices of Tolerance, RISET, The ONE Study and OPTISTEM projects. The authors would like to thank all members of TRIG past and present for their valuable contributions to the data reviewed herein, particularly Ryoichi Goto for help with the figure outlines. 


\section{Figure Legends}

Figure 1 Mechanisms used by adaptive regulatory immune cells in transplantation

Figure 2 Mechanisms used by innate regulatory immune cells in transplantation

Figure 3 Potential clinical application of immune regulatory cell therapy

The authors have no conflicts of interest.

\section{References}

1. Wood, K.J. \& Goto, R. Mechanisms of Rejection: Current Perspectives. Transplantation 93, 110 10.1097/TP.1090b1013e31823cab31844 (2012).

2. Billingham, R.E., Brent, L. \& Medawar, P.B. Actively acquired tolerance of foreign cells. Nature 172, 603 - 606 (1953).

3. Hall, B.M., Jelbart, M.E. \& Dorsch, S.E. Suppressor T cells in rats with prolonged cardiac allograft survival after treatment with cyclosporine. Transplantation 37, 595-600 (1984).

4. Hall, B., Jelbart, M., Gurley, K. \& Dorsch, S. Specific unresponsiveness in rats with prolonged cardiac allograft survival after treatment with cyclosporine. Mediation of specific suppression by T helper/inducer cells. Journal of Experimental Medicine 162, 1683 - 1694 (1985).

5. Quigley, R.L., Wood, K.J. \& Morris, P.J. Mediation of the induction of immunologic unresponsiveness following antigen pretreatment by a CD4 (W3/25 ) T cell appearing transiently in the splenic compartment and subsequently in the TDL. Transplantation 47, 689 - 696 (1989).

6. Hara, M. et al. IL-10 is required for regulatory T cells to mediate tolerance to alloantigens in vivo. J Immunol 166, 3789 - 3796 (2001).

7. Taylor, P.A., Lees, C.J. \& Blazar, B.R. The infusion of ex vivo activated and expanded CD4+CD25+ immune regulatory cells inhibits graft-versus-host disease lethality. Blood 99, 3493-3499 (2002).

8. Sakaguchi, S., Sakaguchi, N., Asano, M., Itoh, M. \& Toda, M. Immunologic self tolerance maintained by activated T cells expressing IL-2 receptor alpha chains (CD25). Breakdown of a single mechanism of self tolerance causes various autoimmune diseases. J Immunol 155, 1151 - 1164 (1995).

9. West, L. et al. ABO-incompatible heart transplantation in infants. New England Journal of Medicine 344, 793 - 800 (2001).

10. Alexander, S.I. et al. Chimerism and Tolerance in a Recipient of a Deceased-Donor Liver Transplant. N Engl J Med 358, 369-374 (2008).

11. Takatsuki, M. et al. Weaning of immunosuppression in living donor liver transplant recipients. Transplantation 72, 449 - 454 (2001).

12. Kawai, T. et al. HLA-Mismatched Renal Transplantation without Maintenance Immunosuppression. N Engl J Med 358, 353-361 (2008).

13. Li, Y. et al. Analyses of Peripheral Blood Mononuclear Cells in Operational Tolerance After Pediatric Living Donor Liver Transplantation. American Journal of Transplantation 4, 21182125 (2004).

14. Martinez-Llordella, M. et al. Multiparameter Immune Profiling of Operational Tolerance in Liver Transplantation. American Journal of Transplantation 7, 309-319 (2007). 
15. Sagoo, P. et al. Development of a cross-platform biomarker signature to detect renal transplant tolerance in humans. The Journal of Clinical Investigation 120, 1848-1861 (2010).

16. Newell, K.A. et al. Identification of a B cell signature associated with renal transplant tolerance in humans. The Journal of Clinical Investigation 120, 1836-1847 (2010).

17. Brouard, S. et al. Identification of a peripheral blood transcriptional biomarker panel associated with operational renal allograft tolerance. Proceedings of the National Academy of Sciences 104, 15448-15453 (2007).

18. Wood, K.J. \& Sakaguchi, S. Regulatory $T$ cells in transplantation tolerance. Nature Immunology Reviews 3, 199 - 210 (2003).

19. Sakaguchi, S., Miyara, M., Costantino, C.M. \& Hafler, D.A. FOXP3+ regulatory T cells in the human immune system. Nat Rev Immunol 10, 490-500 (2010).

20. Edinger, M. et al. CD4+CD25+ regulatory T cells preserve graft-versus-tumor activity while inhibiting graft-versus-host disease after bone marrow transplantation. Nature Medicine $\mathbf{9}$, 1144-1150 (2003).

21. Clark, F.J. et al. Chronic graft-versus-host disease is associated with increased numbers of peripheral blood CD4+CD25high regulatory T cells. Blood 103, 2410-2416 (2004).

22. Reibke, R. et al. CD8+ regulatory T cells generated by neonatal recognition of peripheral selfantigen. Proc. Natl. Acad. Sci. 103, 15142-15147 (2006).

23. Vlad, G., Cortesini, R. \& Suciu-Foca, N. CD8+ T suppressor cells and the ILT3 master switch. Human Immunology 69, 681-686 (2008).

24. Li, X.L. et al. Mechanism and Localization of CD8 Regulatory T Cells in a Heart Transplant Model of Tolerance. J. Immunol. 185, 823-833 (2010).

25. Thomson, C., Lee, B. \& Zhang, L. Double-negative regulatory T cells. Immunologic Research 35, 163-177 (2006).

26. Monteiro, M. et al. Identification of Regulatory Foxp3+ Invariant NKT Cells Induced by TGF- $\beta$. The Journal of Immunology 185, 2157-2163 (2010).

27. Zeng, D. et al. Bone marrow NK1.1- and NK 1.1+ T cells reciprocally regulate acute graft versus host disease. Blood 99, 1449 - 1457 (1999).

28. Hayday, A. \& Tigelaar, R. Immunoregulation in the tissues by [gamma][delta] T cells. Nat Rev Immunol 3, 233-242 (2003).

29. Josefowicz, S.Z. \& Rudensky, A. Control of Regulatory T Cell Lineage Commitment and Maintenance. Immunity 30, 616-625 (2009).

30. Yang, J. et al. Allograft Rejection Mediated by Memory T Cells Is Resistant to Regulation. Proceedings of the National Academy of Sciences USA 104, 19954 - 19959 (2007).

31. Hamano, K., Rawsthorne, M., Bushell, A., Morris, P. \& Wood, K. Evidence that the continued presence of the organ graft and not peripheral donor microchimerism is essential for the maintenance of tolerance to alloantigen in anti-CD4 treated recipients. Transplantation $\mathbf{6 2}$, 856 - 860 (1996).

32. Tullius, S. et al. Chronically rejected rat kidney allografts induce donor-specific tolerance. Transplantation 64, 158 - 161 (1997).

33. Steger, U., Kingsley, C.I., Karim, M., Bushell, A.R. \& Wood, K.J. CD25+CD4+ Regulatory T Cells Develop in Mice Not Only During Spontaneous Acceptance of Liver Allografts but Also After Acute Allograft Rejection. Transplantation 82, 1202-1209 1210.1097/1201.tp.0000235913.0000258337.b0000235914 (2006).

34. Francis, R.S. et al. Induction of transplantation tolerance converts potential effector T cells into graft-protective regulatory T cells. European Journal of Immunology 41, 726-738 (2011).

35. Wood, K.J., Bushell, A. \& Jones, N.D. Immunologic unresponsiveness to alloantigen in vivo: a role for regulatory T cells. Immunological Reviews 241, 119-132 (2011).

36. Graca, L. et al. Both CD4+CD25+ and CD4+CD25- Regulatory Cells Mediate Dominant Transplantation Tolerance. J Immunol 168, 5558-5565 (2002). 
37. Francis, R.S. et al. Induction of transplantation tolerance converts potential effector T cells into graft protective regulatory T cells. European Journal of Immunology in press (2011).

38. Feng, G. et al. Functional Regulatory T Cells Produced by Inhibiting Cyclic Nucleotide Phosphodiesterase Type 3 Prevent Allograft Rejection. Science Translational Medicine 3, 83 ra40 (2011).

39. Feng, G., Wood, K. \& Bushell, A. Interferon-gamma conditioning ex vivo generates CD25+CD62L+Foxp3+ regulatory $T$ cells that prevent allograft rejection: potential avenues for cellular therapy. Transplanation 86, 578-589 (2008).

40. Hester, J., Schiopu, A., Nadig, S.N. \& Wood, K.J. Low dose rapamycin treatment increases the ability of human regulatory $\mathrm{T}$ cells to inhibit transplant arteriosclerosis in vivo $\mathrm{Am}$. $\mathrm{J}$. Transplant. in press (2012).

41. Kingsley, C.I., Karim, M., Bushell, A.R. \& Wood, K.J. CD25+CD4+ Regulatory T Cells Prevent Graft Rejection: CTLA-4- and IL-10-Dependent Immunoregulation of Alloresponses. J Immunol 168, 1080-1086 (2002).

42. McMurchy, A.N., Bushell, A., Levings, M.K. \& Wood, K.J. Moving to tolerance: Clinical application of T regulatory cells. Seminars in Immunology 23, 304-313 (2011).

43. Grohmann, U. et al. CTLA-4lg regulates tryptophan catabolism in vivo. Nature Immunology 3, 1097 - 1101 (2002).

44. Rubtsov, Y.P. et al. Regulatory T Cell-Derived Interleukin-10 Limits Inflammation at Environmental Interfaces. Immunity 28, 546-558 (2008).

45. Wing, K. et al. CTLA-4 Control over Foxp3+ Regulatory T Cell Function. Science 322, 271-275 (2008).

46. Chaturvedi, V., Collison, L.W., Guy, C.S., Workman, C.J. \& Vignali, D.A.A. Cutting Edge: Human Regulatory T Cells Require IL-35 To Mediate Suppression and Infectious Tolerance. The Journal of Immunology 186, 6661-6666 (2011).

47. Andersson, J. et al. CD4+FoxP3+ regulatory T cells confer infectious tolerance in a TGF- $\beta$ dependent manner. The Journal of Experimental Medicine 205, 1975-1981 (2008).

48. Collison, L.W. et al. The inhibitory cytokine IL-35 contributes to regulatory T-cell function. Nature 450, 566-569 (2007).

49. Carvalho-Gaspar, M. et al. Location and Time-Dependent Control of Rejection by Regulatory T Cells Culminates in a Failure to Generate Memory T Cells. J Immunol 180, 6640-6648 (2008).

50. Rosenblum, M.D. et al. Response to self antigen imprints regulatory memory in tissues. Nature 480, 538-542 (2011).

51. Graca, L., Cobbold, S.P. \& Waldmann, H. Identification of Regulatory T Cells in Tolerated Allografts. J. Exp. Med. 195, 1641-1646 (2002).

52. Kendal, A.R. et al. Sustained suppression by Foxp3+ regulatory T cells is vital for infectious transplantation tolerance. The Journal of Experimental Medicine (2011).

53. Groux, H., Bigler, M., de Vries, J.E. \& Roncarolo, M.G. Interleukin-10 induces a long-term antigen specific anergic state in human CD4+ T cells. Journal of Experimental Medicine 184, $19-29$ (1996).

54. Lider, O., Reshef, T., Beraud, E., Ben-Nun, A. \& Cohen, I. Anti-idioptypic network induced by T cell vaccination agains experimental autoimmune encephalomyelitis. Science 239, 181 183 (1988).

55. Hutchinson, I.V. Suppressor T cells in allogeneic models. Transplantation 41, 547 - 555 (1986).

56. Jiang, H. et al. Murine CD8+ T cells that specifically delete autologous CD4+ T cells expressing VB8 TCR: a role of the Qa-1 molecule. Immunity 2, 185-194 (1995).

57. Simpson, E. Suppression of the immune response by cytotoxic T cells. Nature 336, 426-426 (1988). 
58. Dorf, M., Kuchroo, V. \& collins, M. Suppressor T cells: some answers but more questions. Immunology Today 13, 241 - 243 (1992).

59. Dorf, M.E. \& Benacerraf, B. Suppressor Cells and Immunoregulation. Annual Review of Immunology 2, 127-157 (1984).

60. Liu, Z., Tugulea, S., Cortesini, R., Lederman, S. \& Suciu-Foca, N. Inhibition of CD40 signaling pathway in antigen presenting cells by T suppressor cells. Human Immunology 60, 568 - 574 (1999).

61. Trzonkowski, P., Zilvetti, M., Friend, P. \& Wood, K.J. Recipient Memory-Like Lymphocytes Remain Unresponsive to Graft Antigens After CAMPATH-1H Induction with Reduced Maintenance Immunosuppression. Transplantation 82, 1342-1351 (2006).

62. Trzonkowski Homeostatic Repopulation by CD28-CD8 T Cells in Alemtuzumab-Depleted Kidney Transplant Recipients Treated With Reduced Immunosuppression. American journal of transplantation 8, 338-347 (2008).

63. Cai, J. et al. Minor H Antigen HA-1-specific Regulator and Effector CD8+ T Cells, and HA-1 Microchimerism, in Allograft Tolerance. The Journal of Experimental Medicine 199, 10171023 (2004).

64. Zhang, Z., Yang, L., Young, K., DuTemple, B. \& Zhang, L. Identification of a previously unknown antigen-specific regulatory $\mathrm{T}$ cell and its mechanism of suppression. Nature Medicine 6, 782 - 789 (2000).

65. Ford, M.S., Young, K.J., Zhang, Z., Ohashi, P.S. \& Zhang, L. The Immune Regulatory Function of Lymphoproliferative Double Negative T Cells In Vitro and In Vivo. J. Exp. Med. 196, 261267 (2002).

66. Young, K.J., DuTemple, B., Phillips, M.J. \& Zhang, L. Inhibition of Graft-Versus-Host Disease by Double-Negative Regulatory T Cells. The Journal of Immunology 171, 134-141 (2003).

67. Ford, M.S. et al. Peptide-activated double-negative T cells can prevent autoimmune type-1 diabetes development. European Journal of Immunology 37, 2234-2241 (2007).

68. Hill, M. et al. Cell Therapy With Autologous Tolerogenic Dendritic Cells Induces Allograft Tolerance Through Interferon-Gamma and Epstein-Barr Virus-Induced Gene 3. American Journal of Transplantation 11, 2036-2045 (2011).

69. Fischer, K. et al. Isolation and characterization of human antigen-specific TCR $\alpha \beta+$ CD4-CD8double-negative regulatory T cells. Blood 105, 2828-2835 (2005).

70. Mclver, Z. et al. Double-negative regulatory T cells induce allotolerance when expanded after allogeneic haematopoietic stem cell transplantation. British Journal of Haematology 141, 170-178 (2008).

71. Jukes, J.-P., Wood, K.J. \& Jones, N.D. Natural Killer T Cells: A Bridge to Tolerance or a Pathway to Rejection? Transplantation 84, 679-681 610.1097/1001.tp.0000280551.0000278156.ac (2007).

72. Palathumpat, V., Dejbakhsh-Jones, S., Holm, B. \& Strober, S. Different subsets of T cells in the adult mouse bone marrow and spleen induce or suppress acute graft-versus-host disease. The Journal of Immunology 149, 808-817 (1992).

73. Pillai, A.B., George, T.I., Dutt, S. \& Strober, S. Host natural killer T cells induce an interleukin4-dependent expansion of donor CD4+CD25+Foxp3+ T regulatory cells that protects against graft-versus-host disease. Blood 113, 4458-4467 (2009).

74. Leveson-Gower, D.B. et al. Low doses of natural killer T cells provide protection from acute graft-versus-host disease via an IL-4-dependent mechanism. Blood 117, 3220-3229 (2011).

75. Martinez-Llordella, M. et al. Using transcriptional profiling to develop a diagnostic test of operational tolerance in liver transplant recipients. The Journal of clinical investigation 118, 2845-2857 (2008).

76. Li, Y. et al. Analyses of peripheral blood mononuclear cells in operational tolerance after pediatric living donor liver transplantation. Am J Transplant 4, 2118-2125 (2004). 
77. Girardi, M. et al. Resident Skin-specific $\gamma \delta$ T Cells Provide Local, Nonredundant Regulation of Cutaneous Inflammation. The Journal of Experimental Medicine 195, 855-867 (2002).

78. Pallier, A. et al. Patients with drug-free long-term graft function display increased numbers of peripheral B cells with a memory and inhibitory phenotype. Kidney Int 78, 503-513 (2010).

79. Mauri, C. \& Blair, P.A. Regulatory B cells in autoimmunity: developments and controversies. Nat Rev Rheumatol 6, 636-643 (2010).

80. Fillatreau, S., Gray, D. \& Anderton, S.M. Not always the bad guys: B cells as regulators of autoimmune pathology. Nat Rev Immunol 8, 391-397 (2008).

81. Fillatreau, S., Sweenie, C.H., McGeachy, M.J., Gray, D. \& Anderton, S.M. B cells regulate autoimmunity by provision of IL-10. Nat Immunol 3, 944-950 (2002).

82. Mauri, C., Gray, D., Mushtaq, N. \& Londei, M. Prevention of Arthritis by Interleukin 10producing B Cells. The Journal of Experimental Medicine 197, 489-501 (2003).

83. Blair, P.A. et al. CD19+CD24hiCD38hi B Cells Exhibit Regulatory Capacity in Healthy Individuals but Are Functionally Impaired in Systemic Lupus Erythematosus Patients. Immunity 32, 129-140 (2010).

84. Tu, W. et al. Efficient generation of human alloantigen-specific CD4+ regulatory $T$ cells from naive precursors by CD40-activated B cells. Blood 112, 2554-2562 (2008).

85. Zheng, J., Liu, Y., Lau, Y.-L. \& Tu, W. CD40-activated B cells are more potent than immature dendritic cells to induce and expand CD4+ regulatory T cells. Cell Mol Immunol 7, 44-50 (0000).

86. Ding, Q. et al. Regulatory B cells are identified by expression of TIM-1 and can be induced through TIM-1 ligation to promote tolerance in mice. The Journal of Clinical Investigation 121, 3645-3656 (2011).

87. Le Texier, L. et al. Long-Term Allograft Tolerance Is Characterized by the Accumulation of B Cells Exhibiting an Inhibited Profile. American Journal of Transplantation, no-no (2010).

88. Heidt, S., Hester, J., Shankar, S., Friend, P. \& Wood, K.J. B cell repopulation after alemtuzum induction - transient increase in transitional $B$ cells and long term dominance of naive $B$ cells. American Journal of Transplantation in press (2012).

89. Hester, J. et al. Th17 cells in alemtuzumab-treated patients. The effect of long-term maintenance immunosuppressive therapy. Transplantation 91, 744-750 (2011).

90. Bloom, D.D. et al. CD4+CD25+FOXP3+ Regulatory T Cells Increase De Novo in Kidney Transplant Patients After Immunodepletion with Campath-1H. American Journal of Transplantation 8, 793-802 (2008).

91. Chung, J.B. et al. Incomplete Activation of CD4 T Cells by Antigen-Presenting Transitional Immature B Cells: Implications for Peripheral B and T Cell Responsiveness. The Journal of Immunology 171, 1758-1767 (2003).

92. Niimi, M. et al. The role of the CD40 pathway in alloantigen induced hyporesponsiveness in vivo. J Immunol 161, 5331 - 5337 (1998).

93. Murray, P.J. \& Wynn, T.A. Protective and pathogenic functions of macrophage subsets. Nat Rev Immunol 11, 723-737 (2011).

94. Li, X.C. The Significance of Non-T-Cell Pathways in Graft Rejection: Implications for Transplant Tolerance. Transplantation 90, 1043-1047 1010.1097/TP.1040b1013e3181efcfe1049 (2010).

95. Fleming, B.D. \& Mosser, D.M. Regulatory macrophages: Setting the Threshold for Therapy. European Journal of Immunology 41, 2498-2502 (2011).

96. Tiemessen, M.M. et al. CD4+CD25+Foxp3+ regulatory T cells induce alternative activation of human monocytes/macrophages. Proceedings of the National Academy of Sciences 104, 19446-19451 (2007).

97. Wong, S.-C. et al. Macrophage polarization to a unique phenotype driven by B cells. European Journal of Immunology 40, 2296-2307 (2010). 
98. Hutchinson, J.A. et al. Cutting Edge: Immunological Consequences and Trafficking of Human Regulatory Macrophages Administered to Renal Transplant Recipients. The Journal of Immunology 187, 2072-2078 (2011).

99. Hashimoto, D. et al. Pretransplant CSF-1 therapy expands recipient macrophages and ameliorates GVHD after allogeneic hematopoietic cell transplantation. The Journal of Experimental Medicine 208, 1069-1082 (2011).

100. Steiman, R. \& Witmer, M. Lymphoid dendritic cells are potent stimulators of the primary mixed leukocyte reaction in mice. Proc. Natl. Acad. Sci. 75, 5132-5136 (1978).

101. Morelli, A.E. \& Thomson, A.W. Tolerogenic dendritic cells and the quest for transplant tolerance. Nat Rev Immunol 7, 610-621 (2007).

102. van Kooten, C. et al. Dendritic Cells as a Tool to Induce Transplantation Tolerance: Obstacles and Opportunities. Transplantation 91, 2-7 10.1097/TP.1090b1013e31820263b31820263 (2011).

103. Steinman, R.M., Hawiger, D. \& Nussenzweig, M.C. TOLEROGENIC DENDRITIC CELLS*. Annual Review of Immunology 21, 685-711 (2003).

104. Lu, L., McCaslin, D., Starzl, T.E. \& Thomson, A.W. BONE MARROW-DERIVED DENDRITIC CELL PROGENITORS (NLDC 145+, MHC CLASS II+, B7-1dim, B7-2-) INDUCE ALLOANTIGEN-SPECIFIC HYPORESPONSIVENESS IN MURINE T LYMPHOCYTES1,2. Transplantation 60, 1539\&hyhen;1545 (1995).

105. Fu, F. et al. Costimulatory molecule-deficient dendritic cell progenitors (MHC class $\mathrm{II}^{+}$, $\mathrm{CD} 80^{\mathrm{dim}}, \mathrm{CD}^{\circ}$ ) prolong cardiac allograft survival in nonimmunosupressed recipients. Transplantation 62, 659-665 (1996).

106. Lutz, M. et al. Immature dendritic cells generated with low doses of GM-CSF in the absence of IL-4 are maturation resistant and prolong allograft survival in vivo. European Journal of Immunology 30, 1813 - 1822 (2000).

107. Roelen, D. et al. Prolongation of skin graft survival by modulation of the alloimmune response with alternatively activated dendritic cells. Transplantation 76, 1608 - 1615 (2003).

108. Sato, K., Yamashita, N., Yamashita, N., Baba, M. \& Matsuyama, T. Regulatory Dendritic Cells Protect Mice from Murine Acute Graft-versus-Host Disease and Leukemia Relapse. Immunity 18, 367-379 (2003).

109. Lu, L. et al. Blockade of the CD40-CD40 ligand pathway potentiates the capacity of donorderived dendritic cell progenitors to induce long-term cardiac allograft survival. Transplantation 64, 1808 - 1815 (1997).

110. Swiecki, M. \& Colonna, M. Unraveling the functions of plasmacytoid dendritic cells during viral infections, autoimmunity, and tolerance. Immunological Reviews 234, 142-162 (2010).

111. Ochando, J.C. et al. Alloantigen-presenting plasmacytoid dendritic cells mediate tolerance to vascularized grafts. Nat Immunol 7, 652-662 (2006).

112. Gilliet, M. \& Liu, Y.-J. Generation of Human CD8 T Regulatory Cells by CD40 Ligand-activated Plasmacytoid Dendritic Cells. J. Exp. Med. 195, 695-704 (2002).

113. Mazariegos, G.V. et al. Dendritic Cell Subset Ratio in Tolerant, Weaning and Non-Tolerant Liver Recipients Is Not Affected by Extent of Immunosuppression. American Journal of Transplantation 5, 314-322 (2005).

114. Tokita, D. et al. High PD-L1/CD86 Ratio on Plasmacytoid Dendritic Cells Correlates With Elevated T-Regulatory Cells in Liver Transplant Tolerance. Transplantation 85, 369-377 310.1097/TP.1090b1013e3181612ded (2008).

115. Matta, B.M., Castellaneta, A. \& Thomson, A.W. Tolerogenic plasmacytoid DC. European Journal of Immunology 40, 2667-2676 (2010).

116. Boros, P., Ochando, J.C., Chen, S.-H. \& Bromberg, J.S. Myeloid-derived suppressor cells: Natural regulators for transplant tolerance. Human Immunology 71, 1061-1066 (2010).

117. Haile, L.A. et al. Myeloid-Derived Suppressor Cells in Inflammatory Bowel Disease: A New Immunoregulatory Pathway. Gastroenterology 135, 871-881.e875 (2008). 
118. Gallina, G. et al. Tumors induce a subset of inflammatory monocytes with immunosuppressive activity on CD8+ T cells. The Journal of Clinical Investigation 116, 2777 2790 (2006).

119. Garcia, M.R. et al. Monocytic suppressive cells mediate cardiovascular transplantation tolerance in mice. The Journal of Clinical Investigation 120, 2486-2496 (2010).

120. Chou, H.-S. et al. Myeloid-Derived Suppressor Cells Protect Islet Transplants by B7-H1 Mediated Enhancement of $T$ Regulatory Cells. Transplantation 93, 272-282 210.1097/TP.1090b1013e31823ffd31839 (2012).

121. Dugast, A.-S. et al. Myeloid-Derived Suppressor Cells Accumulate in Kidney Allograft Tolerance and Specifically Suppress Effector T Cell Expansion. The Journal of Immunology 180, 7898-7906 (2008).

122. Yamada, A. et al. Cutting Edge: Recipient MHC Class II Expression Is Required to Achieve Long-Term Survival of Murine Cardiac Allografts After Costimulatory Blockade. J Immunol 167, 5522-5526 (2001).

123. De Wilde, V. et al. Endotoxin-Induced Myeloid-Derived Suppressor Cells Inhibit Alloimmune Responses via Heme Oxygenase-1. American Journal of Transplantation 9, 2034-2047 (2009).

124. English, K., French, A. \& Wood, K.J. Mesenchymal Stromal Cells: Facilitators of Successful Transplantation? Cell Stem Cell 7, 431-442 (2010).

125. Ding, Y. et al. Mesenchymal Stem Cells prevent the rejection of fully allogenic islet grafts by the immunosuppressive activity of Matrix Metalloproteinase-2 and -9. Diabetes 58, 1797 1806 (2009).

126. English, K. et al. Cell contact, prostaglandin E-2 and transforming growth factor beta 1 play non-redundant roles in human mesenchymal stem cell induction of CD4(+)CD25(High)forkhead box P3(+) regulatory T cells. Clin Exp Immunol 156, 149-160 (2009).

127. Casiraghi, F. et al. Pretransplant infusion of mesenchymal stem cells prolongs the survival of a semiallogeneic heart transplant through the generation of regulatory T cells. J Immunol 181, 3933-3946 (2008).

128. Zhang, B. et al. Mesenchymal stem cells induce mature dendritic cells into a novel Jagged-2dependent regulatory dendritic cell population. Blood 113, 46-57 (2009).

129. Ge, W. et al. Infusion of Mesenchymal Stem Cells and Rapamycin Synergize to Attenuate Alloimmune Responses and Promote Cardiac Allograft Tolerance. American Journal of Transplantation 9, 1760-1772 (2009).

130. Larsen, C., Morris, P. \& Austyn, J. Migration of dendritic leukocytes form cardiac allografts into host spleens: a novel pathway for initiation of rejection. Journal of Experimental Medicine 171, 307 - 314 (1990).

131. Lakkis, F., Arakelov, A., Konienczny, B. \& Inoue, Y. Immunologic 'ignorance' of vascularised organ transplants in the absence of secondary lymphoid tissue. Nature Medicine 6, 686 - 688 (2000).

132. Pearl, J.P. et al. Immunocompetent T-Cells with a Memory-Like Phenotype are the Dominant Cell Type Following Antibody-Mediated T-Cell Depletion. American Journal of Transplantation 5, 465-474 (2005).

133. Lopez, M., Clarkson, M.R., Albin, M., Sayegh, M.H. \& Najafian, N. A Novel Mechanism of Action for Anti-Thymocyte Globulin: Induction of CD4+CD25+Foxp3+ Regulatory T Cells. Journal of the American Society of Nephrology 17, 2844-2853 (2006).

134. Salama, A.D., Najafian, N., Clarkson, M.R., Harmon, W.E. \& Sayegh, M.H. Regulatory CD25+ T Cells in Human Kidney Transplant Recipients. J Am Soc Nephrol 14, 1643-1651 (2003).

135. Akl, A. et al. An investigation to assess the potential of CD25highCD4+ T cells to regulate responses to donor alloantigens in clinically stable renal transplant recipients. Transplant International 21, 65-73 (2008). 
136. Battaglia, M. et al. Rapamycin Promotes Expansion of Functional CD4+CD25+FOXP3+ Regulatory T Cells of Both Healthy Subjects and Type 1 Diabetic Patients. The Journal of Immunology 177, 8338-8347 (2006).

137. Bushell, A. \& Wood, K. GITR Ligation Blocks Allograft Protection by Induced CD25+CD4+ Regulatory T Cells without Enhancing Effector T-Cell Function. American Journal of Transplantation 7, 759-768 (2007).

138. Warnecke, G., Bushell, A., Nadig, S. \& Wood, K.J. Regulation of transplant arteriosclerosis by CD25+CD4+ T cells generated to alloantigen in vivo. Transplantation 83, 1459 -1465 (2007).

139. Nadig, S.N. et al. In vivo prevention of transplant arteriosclerosis by ex vivo-expanded human regulatory T cells. Nat Med 16, 809-813 (2010).

140. Ermann, J. et al. Only the CD62L+ subpopulation of CD4+CD25+ regulatory $T$ cells protects from lethal acute GVHD. Blood 105, 2220-2226 (2005).

141. Trzonkowski, P. et al. First-in-man clinical results of the treatment of patients with graft versus host disease with human ex vivo expanded CD4+CD25+CD127- T regulatory cells. Clinical Immunology 133, 22-26 (2009).

142. Brunstein, C.G. et al. Infusion of ex vivo expanded T regulatory cells in adults transplanted with umbilical cord blood: safety profile and detection kinetics. Blood 117, 1061-1070 (2011).

143. Di lanni, M. et al. Tregs prevent GVHD and promote immune reconstitution in HLAhaploidentical transplantation. Blood 117, 3921-3928 (2011).

144. Shin, H.-J. et al. Rapamycin and IL-2 reduce lethal acute graft-versus-host disease associated with increased expansion of donor type CD4+CD25+Foxp3+ regulatory T cells. Blood 118, 2342-2350 (2011).

145. Koreth, J. et al. Interleukin-2 and Regulatory T Cells in Graft-versus-Host Disease. New England Journal of Medicine 365, 2055-2066 (2011).

146. Nguyen, V.H. et al. The impact of regulatory T cells on T-cell immunity following hematopoietic cell transplantation. Blood 111, 945-953 (2008).

147. Bushell, A., Jones, E., Gallimore, A. \& Wood, K.J. The generation of CD25+CD4+ regulatory cells that prevent allograft rejection does not compromise immunity to a viral protein. $J$ Immunol 174, 3290 - 3297 (2005).

148. LeBlanc, K. et al. Mesenchymal stem cells for treatment of steroid-resistant, severe, acute graft-versus-host disease: a phase II study. Lancet 371, 1579-1586 (2008).

149. MacMillan, M.L., Blazer, B.R., DeFor, T.E. \& Wagner, J.E. Transplantation of ex-vivo cultureexpanded parental haploidentical mesenchymal stem cells to promote engraftment in pediatric recipients of unrelated donor umbilical cord blood: results of a phase I-II clinical trial. Bone Marrow Transpl 43, 447-454 (2009).

150. Mills, C.R. Osiris Therapeutics Announces Preliminary Results for Prochymal Phase III GvHD Trials. (Press Release) (Cited 1 November 2009); available from: http://investor.osiris.com/releasedetail.cfm?ReleaselD=407404

(2009).

151. Tan, J. et al. Induction Therapy With Autologous Mesenchymal Stem Cells in Living-Related Kidney Transplants. JAMA: The Journal of the American Medical Association 307, 1169-1177 (2012).

152. Giannoukakis, N., Phillips, B., Finegold, D., Harnaha, J. \& Trucco, M. Phase I (Safety) Study of Autologous Tolerogenic Dendritic Cells in Type 1 Diabetic Patients. Diabetes Care 34, 20262032 (2011).

153. Naranjo-Gomez, M. et al. Comparative study of clinical grade human tolerogenic dendritic cells. Journal of Translational Medicine 9, 89 (2011). 


\section{Glossary terms:}

graft versus host disease

(GVHD) Tissue damage in a recipient of allogeneic transplanted tissue (usually a bone marrow transplant) that results from the activity of donor cytotoxic T lymphocytes that recognize the tissue of the recipient as foreign. GVHD varies markedly in severity, but can be life threatening in severe cases. Typically, damage to the skin and gut mucosa leads to clinical manifestations.

mixed chimerism

ischemia-reperfusion injury

Natural killer T (NKT) cells

Alemtuzumab

Transitional B cells

Classically activated macrophages

Alternatively activated macrophages

graft-versus-leukaemia effect

tacrolimus

Double negative (DN) T cells 